\title{
Spinal cord injury in the United States Army Special Forces
}

\author{
Presented at the 2020 AANS/CNS Joint Section on Disorders of the Spine and Peripheral Nerves
Remi A. Kessler, BA, ${ }^{1}$ Ansh Bhammar, BS, ${ }^{2}$ Nikita Lakomkin, MD, ${ }^{1}$ Raj K. Shrivastava, MD, ${ }^{1}$ Jonathan J. Rasouli, MD, ${ }^{3}$ Jeremy Steinberger, MD, ${ }^{1}$ Joshua Bederson, MD, ${ }^{1}$ Constantinos G. Hadjipanayis, MD, PhD, ${ }^{1}$ and Deborah L. Benzil, MD ${ }^{3}$ 1Department of Neurosurgery, Icahn School of Medicine at Mount Sinai, New York, New York; '2Johns Hopkins University,
Baltimore, Maryland; and ' ${ }^{2}$ epartment of Neurosurgery, Cleveland Clinic, Cleveland, Ohio

\begin{abstract}
OBJECTIVE Spinal cord injury (SCI) is an area of key interest in military medicine but has not been studied among the US Army Special Forces (SF), the most elite group of US soldiers. SF soldiers make up a disproportionate $60 \%$ of all Special Operations casualties. The objective of this study was to better understand SCI incidence in the SF, its mechanisms of acquisition, and potential areas for intervention by addressing key issues pertaining to protective equipment and body armor use.
\end{abstract}

METHODS An electronic survey questionnaire was formulated with the close collaboration of US board-certified neurosurgeons from the Mount Sinai Hospital and Cleveland Clinic Departments of Neurosurgery, retired military personnel of the SF, and operational staff of the Green Beret Foundation. The survey was sent to approximately 6000 SF soldiers to understand $\mathrm{SCI}$ diagnosis and its associations with various health and military variables.

RESULTS The response rate was 8.2\%. Among the 492 respondents, 94 (19.1\%) self-reported an SCI diagnosis. An airborne operation was the most commonly attributed cause (54.8\%). Moreover, $87.1 \%$ of SF soldiers reported wearing headgear at the time of injury, but only $36.6 \%$ reported wearing body armor, even though body armor use has significantly increased in post-9/11 SF soldiers compared with that in their pre-9/11 counterparts. SCI was significantly associated with traumatic brain injury, arthritis, low sperm count, low testosterone, erectile dysfunction, tinnitus, hyperacusis, sleep apnea, posttraumatic stress disorder, major depressive disorder, and generalized anxiety disorder. Only $16.5 \%$ of SF soldiers diagnosed with $\mathrm{SCI}$ had been rescued via medical evacuation (medevac) for treatment.

CONCLUSIONS A high number of SF soldiers self-reported an SCl diagnosis. Airborne operations landings were the leading cause of $\mathrm{SCl}$, which coincided with warfare tactics employed during the Persian Gulf War, Operation Iraqi Freedom, and other conflicts. A majority of SCls occurred while wearing headgear and no body armor, suggesting the need for improvements in protective equipment use and design. The low rate of medevac rescue for these injuries may suggest that medical rescue was not attainable at the time or that certain SCls were deemed minor at the time of injury.

https://thejns.org/doi/abs/10.3171/2020.7.SPINE20804

KEYWORDS spinal cord injury; trauma; military; combat; airborne; spine

$\mathrm{H}$ ISTORICALLY, military injuries have evolved dramatically to reflect the prevailing combat mechanisms. ' World War I injuries, for example, related to the specifics of trench warfare and nerve gases, whereas World War II was marked by sniper gunshot wounds and flash burns from grenades or explosives. ${ }^{2,3}$ Neurosurgical injuries have been a critical component of modern combat injury morbidity and mortality, leading to extensive research and progress. ${ }^{4}$ The most recent conflicts have in- volved an entirely different mode of destruction-primarily landmines and improvised explosive devices (IEDs) in a guerrilla style, leading to altered military strategies and injury patterns. ${ }^{5}$ Across the military, enhanced personnel protective measures, medical advances, and improved survival have led to an appreciable reduction in casualties but also a concomitant increase in those surviving with significant morbidity.

Combat-related spinal injuries constitute more than

ABBREVIATIONS GBF = Green Beret Foundation; IED = improvised explosive device; medevac = medical evacuation; MFF = Military Free Fall; SCI = spinal cord injury; $\mathrm{SF}=$ Special Forces; $\mathrm{TBI}=$ traumatic brain injury; VA = Department of Veterans Affairs.

SUBMITTED May 6, 2020. ACCEPTED July 1, 2020.

INCLUDE WHEN CITING Published online September 25, 2020; DOI: 10.3171/2020.7.SPINE20804. 
$11 \%$ of all US casualties from the recent Iraq and Afghanistan wars, and studies have estimated that some degree of spine trauma is present in over $38 \%$ of all combat-related casualties. ${ }^{6,7}$ Traumatic spinal cord injury (SCI) is often devastating, resulting in severe impairments to motor and sensory function. Military SCI differs from civilian SCI in that it is more often associated with polytrauma, injury patterns are complex, and initial management must occur in difficult environments with limited access to immediate surgical intervention. ${ }^{7}$ Well-documented long-term effects of SCI include reproductive and sexual impairments, cardiac disease, infections, and mental illness. ${ }^{8}$ Hence, SCI can have a devastating impact on the lives of a soldier and their family, often leading to early discharge and retirement. The loss of experienced and accomplished personnel also impairs wartime preparedness and has massive financial implications for the US Armed Forces, Department of Defense, and Department of Veterans Affairs (VA). In 2011, the VA provided SCI care to 27,000 veterans. ${ }^{9}$ Furthermore, in 2013, the VA's annual cost per patient with SCI and associated disorders was $\$ 44,696$; this results in an estimate of at least $\$ 1.2$ billion in direct costs for treating SCI in veterans annually.

US Army Special Forces (SF) soldiers represent a disproportionate $60 \%$ of all Special Operations casualties. ${ }^{10}$ This is directly related to their missions in high-risk enemy environments and use of unconventional guerrilla warfare, including counterterrorism, hostage rescue, highvalue target manhunts, sabotage, counterinsurgency support, and foreign defense. ${ }^{11}$ Such military operations make these soldiers an extraordinarily unique patient population with distinct exposures and long-term combat missions across the world. Given the changes in numerous military factors and the known consequences of SCI, performing a comprehensive analysis of the demographics and ramifications of SCI among the SF would have considerable value. Despite research efforts in this domain, such an analysis has not been conducted.

The objective of this study was to establish the current profile of war-related SCI in the SF. Identifying the occurrence and mechanisms of acquisition will allow focused efforts on prevention, primarily through addressing potential issues pertaining to protective equipment design and use. Because an understanding of injury in military medicine has historically served as a scaffold for the treatment of civilian trauma, the results of this study are not only critical in understanding SCI in the SF, but can also have implications for the prevention of civilian SCI. ${ }^{12}$

\section{Methods \\ Data Collection and Participant Criteria}

The Green Beret Foundation (GBF) joined with the Departments of Neurosurgery of Mount Sinai (New York, $\mathrm{NY}$ ) and Cleveland Clinic (Cleveland, $\mathrm{OH}$ ) to investigate the prevalence of neurological injury among active duty, separated, and retired members of the US Army SF. An online questionnaire was developed via the collaboration of US board-certified neurosurgeons, retired SF service members, and GBF operational staff. Collected data included military background, demographics, medical and family history, and injuries diagnosed while in service. This self-reported questionnaire was disseminated to approximately $6000 \mathrm{SF}$ soldiers in October 2019 via the GBF's extended military network. Inclusion criteria for participation consisted of the obligatory 18 -Series SF qualification and completion of the neurological portion of the questionnaire. Respondents were asked if they had been clinically diagnosed with an SCI. This research was approved by the Mount Sinai Institutional Review Board.

\section{Statistical Analysis}

Descriptive statistics were employed to present a composite of the etiologies of SCI in this population. All statistical tests were conducted on R software (R 3.6.3, R Foundation for Statistical Computing; https://www. r-project.org/). Bivariate statistics were used to explore the relationship between sustaining an SCI and consequent comorbidity and variables of interest. Chi-square tests of independence or Fisher's exact tests, as appropriate, were utilized to test the associations of categorical variables as reported by study participants in the survey questionnaire. Two-tailed independent-samples t-tests were employed when examining any continuous variables in association with an SCI diagnosis. All possible associations between diagnosis of SCI and other responses were tested. Statistical significance was set a priori at 0.05 .

\section{Results}

Four hundred ninety-two respondents $(8.2 \%$ total response rate) met the inclusion criteria. All SF soldiers were male, and the mean age was 51 years. Service in the US Army ranged from 1945 to 2019. Most respondents were directly involved in combat operations (86.8\%), and 43.4\% had completed Military Free Fall (MFF) training, which is the qualification course to become a parachutist. Pre9/11 service members represented $59.8 \%$ of participants, whereas $40.2 \%$ were post-9/11 members. SCI diagnosis was reported by $19.1 \%(n=94)$ of all SF soldiers. There was a significant association between pre-9/11 SF soldiers and SCI diagnosis $\left(\mathrm{n}=492, \chi^{2}[1]=7.65, \mathrm{p}=0.0057\right)$, as $23.1 \%(\mathrm{n}=68)$ of pre-9/11 SF soldiers sustained an SCI compared to $13.1 \%(\mathrm{n}=26)$ of post-9/11 SF soldiers.

\section{Detailed SCI Findings}

Analysis of the SCI cohort $(n=94)$ revealed that $87.2 \%$ $(n=82)$ were directly involved in combat operations and that $51.1 \%(n=48)$ have the MFF qualification. Pre-9/11 SF respondents represented $71.3 \%(n=67)$ of these injured soldiers. There was no significant association between the MFF qualification and sustaining an SCI. The most commonly attributed cause of SCI was an airborne operation (54.8\%; Fig. 1). The vast majority of soldiers $(87.1 \%)$ were wearing headgear at the time of injury, with just 36.6\% wearing any type of body armor (Fig. 2). However, there was a significantly increased use of body armor among post-9/11 SF soldiers at the time of SCI as compared to that in the pre-9/11 SF soldiers $\left(\mathrm{n}=93, \chi^{2}[1]=9.7091, \mathrm{p}\right.$ $=0.0018$; Fig. 3). Only $16.5 \%$ (15/91) of SF soldiers were medical evacuation (medevac) rescued at the time of SCI. 


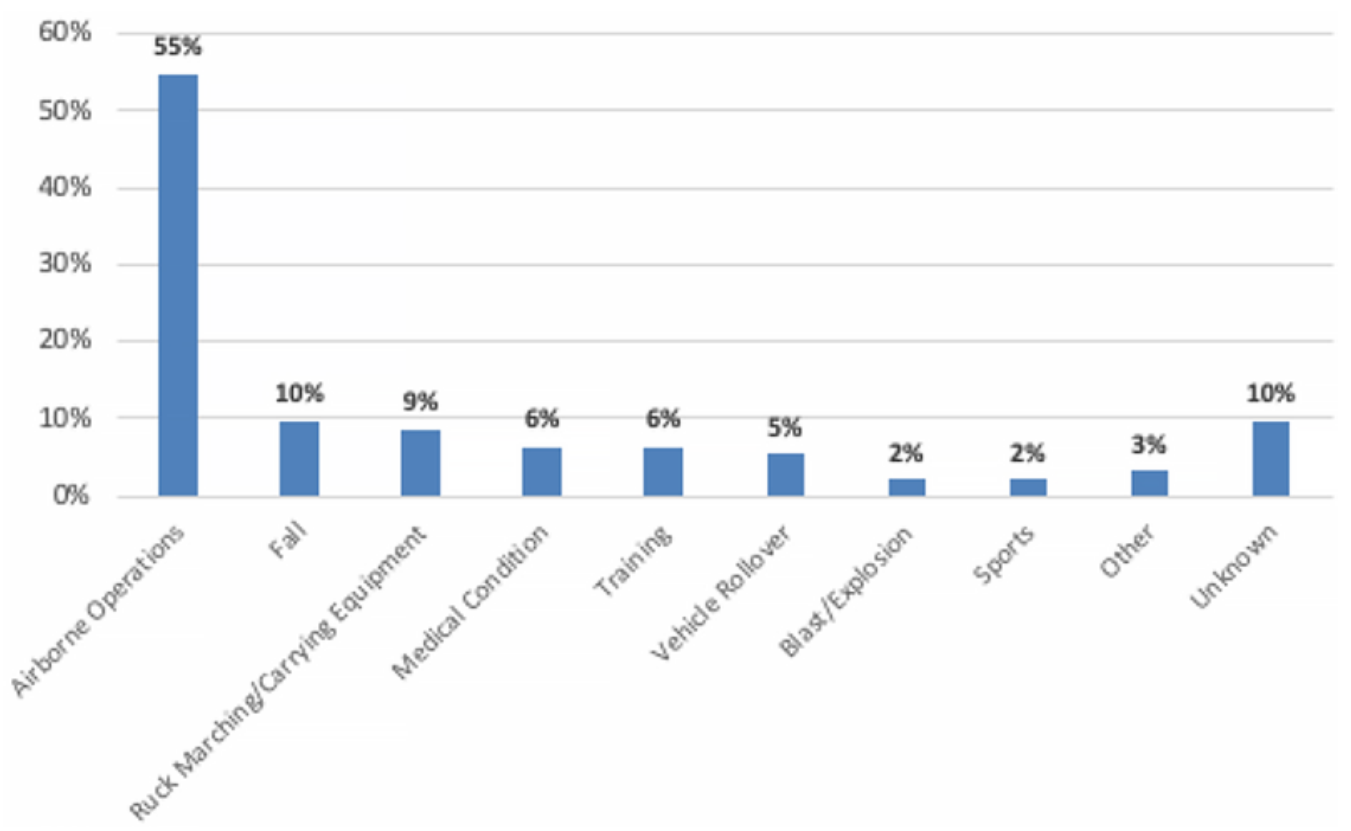

FIG. 1. Attributed causes of $\mathrm{SCl}(\mathrm{n}=93)$ in US Army SF soldiers. Figure is available in color online only.

\section{Comorbid Conditions and Mental IIIness}

SCI was significantly associated with a number of comorbidities (Table 1), including both mild and moderate/severe traumatic brain injury (TBI), low sperm count, low testosterone, erectile dysfunction, tinnitus, hyperacusis, sleep apnea, and arthritis. It was also significantly associated with various mental illnesses, including posttraumatic stress disorder, major depressive disorder, and generalized anxiety disorder.

\section{Disability Claims and VA Rating}

Of those who had sustained an SCI, 79.8\% ( $\mathrm{n}=75)$ reported receiving disability benefits with a mean current VA disability rating of $84.9 / 100$, which was significantly higher than the VA rating of $69.6 / 100$ for those who had not sustained an SCI $(\mathrm{n}=312, \mathrm{t}=4.07, \mathrm{p}<0.0001)$. For those receiving disability benefits, sustaining an SCI was significantly associated with receiving disability compensation for brain injury and spine injury but not for mental illness (Table 2).

\section{Discussion}

War is a constant in history, but the injuries sustained relate specifically to the type of combat and have evolved significantly in the last few conflicts. This study defines the etiologies of SCI in the US Army SF. Understanding the findings should facilitate efforts on prevention, primarily through addressing equipment and headgear design.

While SCI in the military dates back to the US Civil War, SCI during World War II led to the establishment of neurorehabilitation and hospital units dedicated to SCI. ${ }^{13}$ Later, SCIs sustained in the Korean and Vietnam wars led to the triage of wounded soldiers and battlefield helicopter evacuation systems. ${ }^{14}$ A previous systematic review investigating military SCI revealed that it was diagnosed in up to $8 \%$ of soldiers wounded in modern war, with the highest incidence among white males who served in the Marine Corps. ${ }^{15}$ Additionally, the most common SCI location was the thoracic region, followed by lumbosacral and cervical injuries. ${ }^{13}$ Furthermore, past research has indicated that in
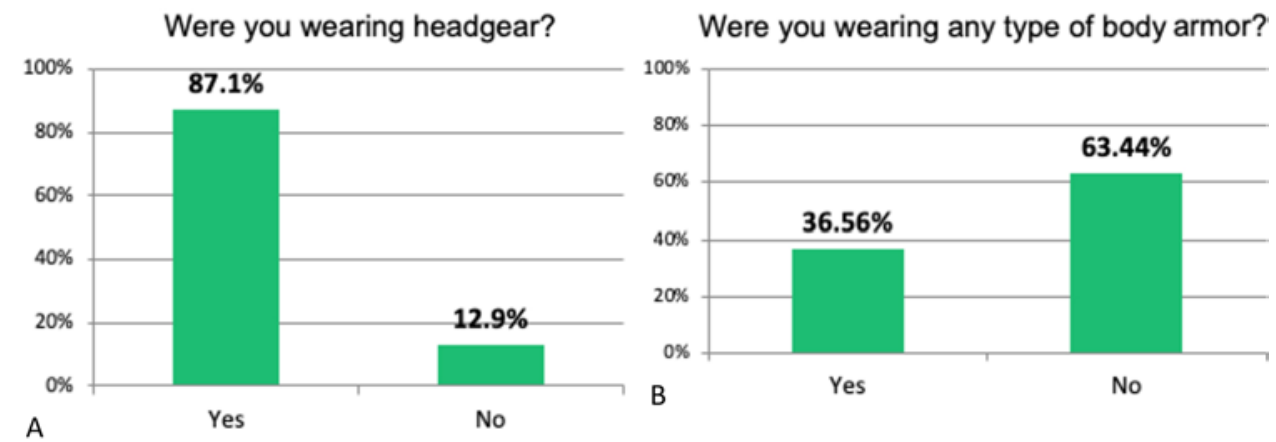

FIG. 2. A: Headgear use in US Army SF soldiers sustaining an $\mathrm{SCl}(\mathrm{n}=93)$. B: Body armor use in US Army SF soldiers sustaining an $\mathrm{SCl}(n=93)$. Figure is available in color online only. 
Were you wearing headgear?

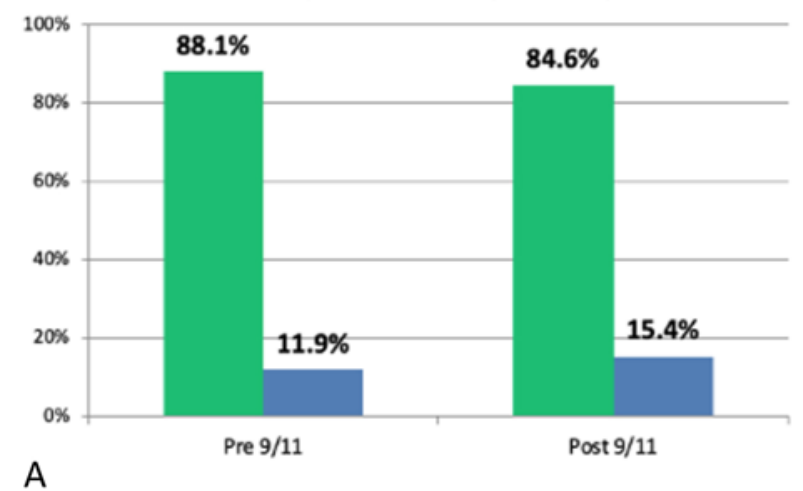

Were you wearing any type of body armor?

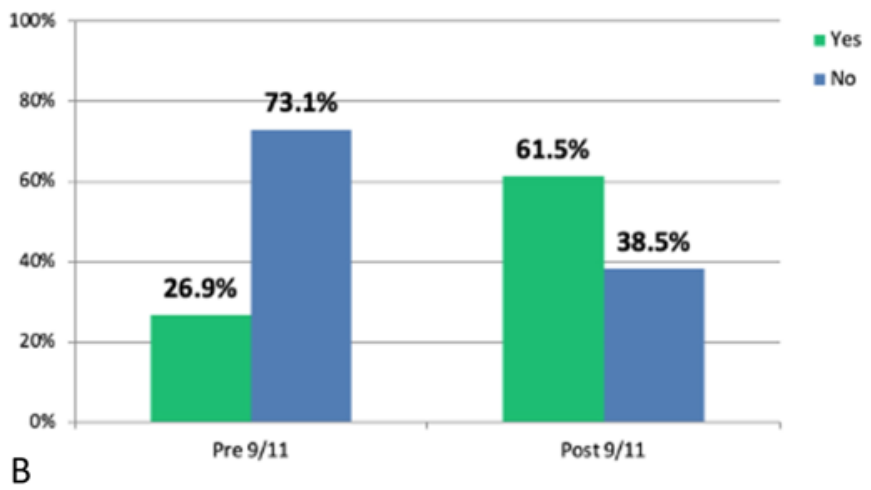

FIG. 3. A: Headgear use was similar between pre- and post-9/11 SF soldiers who sustained an SCI. B: Body armor use was significantly increased in post-9/11 SF soldiers who sustained an SCI compared to that in the pre-9/11 SF soldiers who sustained an $\mathrm{SCl}\left(n=93, \chi^{2}[1]=9.7091, p=0.0018\right)$. Figure is available in color online only.

American combat-wounded soldiers, spine-related injuries were a major cause of medical discharge from the military (14\%). ${ }^{13}$ The present investigation explores SCI in an unexamined front-line cohort of combat military personnel, specifically the US Army SF. Interestingly, airborne operations were reported to be the leading etiology of SCI in this study, in both pre- and post-9/11 service members. While we were unable to determine a rate of SCI equivalent to those reported in these other studies, our study does confirm SCI as a leading injury and a significant driver of disability.

Airborne operations are defined as the aerial delivery of troops and equipment into a combat zone without landing the aircraft, involving static line parachuting, free-fall parachuting, and fast-roping down from a helicopter. They have a history of high casualty rates among members of the US Armed Forces during large-scale worldwide conflicts. ${ }^{16-19}$ Clearly, our data support the ongoing risk when

TABLE 1. Comorbid conditions and mental illness associations with $\mathrm{SCl}$

\begin{tabular}{lccc}
\hline \multirow{2}{*}{$\begin{array}{c}\text { Comorbid } \\
\text { Condition }\end{array}$} & No. of & \multicolumn{2}{c}{ Association w/ SCl } \\
\cline { 3 - 4 } Cases & $\chi^{2}(1)$ & p Value \\
\hline Mild TBI & 492 & 20.8 & $<0.0001$ \\
\hline Moderate/severe TBI & 492 & 19.5 & $<0.0001$ \\
\hline Arthritis & 492 & 11.4 & $\mathbf{0 . 0 0 0 7}$ \\
\hline Low sperm count & 492 & 7.5 & $\mathbf{0 . 0 0 6 3}$ \\
\hline Low testosterone & 492 & 10.9 & $\mathbf{0 . 0 0 0 9}$ \\
\hline Erectile dysfunction & 492 & 5.0 & $\mathbf{0 . 0 2 4 8}$ \\
\hline Tinnitus & 492 & 7.0 & $\mathbf{0 . 0 0 8 1}$ \\
\hline Hyperacusis & 492 & 6.9 & $\mathbf{0 . 0 1 2 2 9}$ \\
\hline Sleep apnea & 492 & 9.5 & $\mathbf{0 . 0 0 2 1}$ \\
\hline PTSD & 491 & 5.50 & $\mathbf{0 . 0 1 9 3}$ \\
\hline MDD & 491 & 12.1 & $\mathbf{0 . 0 0 0 5}$ \\
\hline GAD & 491 & 23.1 & $<0.0001$ \\
\hline
\end{tabular}

$\mathrm{GAD}=$ generalized anxiety disorder; $\mathrm{MDD}=$ major depressive disorder;

PTSD = posttraumatic stress disorder.

Boldface type indicates statistical significance. operations include a significant airborne operations component.

The principles governing military parachuting have remained essentially unchanged since the 1940s. ${ }^{12}$ When a parachutist lands on the ground, the kinetic energy is dissipated via a landing roll, which is the method associated with the least risk of injury and was adopted in 1943 by the US Army (Fig. 4). ${ }^{20}$ While parachute design and mechanics have remained remarkably static for more than 70 years, other aspects of military equipment and experience have changed. Despite this, our study indicates a sustained high SCI incidence over time.

Parachuting injuries can occur upon exit from the aircraft, descent, or landing; the most common spine injuries associated with parachuting occur upon landing on the ground. ${ }^{21,22}$ Severe landing mishaps such as landing backward into a sitting position transfers forces into the lower spine, leading to thoracolumbar compression fractures. ${ }^{23}$ Further force transmission can lead to whiplash injury of the neck. ${ }^{12}$ Closed-head TBI can also occur if the helmeted head strikes the ground with high impact. ${ }^{24}$

Other factors affect injury risk. Parachute casualties increase with higher wind speeds; thus, numerous military forces have established threshold wind speeds for parachuting. ${ }^{21}$ Additionally, the weight of the parachutist is associated with casualty risk, with greater mean weights linked to a greater risk of casualty. ${ }^{25,26}$ The injury risk in military parachuting is higher than that in civilian parachuting because of the heavy equipment that must be borne, multiple parachutists leaving the aircraft simultaneously, nighttime

TABLE 2. Receiving disability compensation and its association with $\mathrm{SCl}$

\begin{tabular}{cccc}
\hline Disability & No. of & \multicolumn{2}{c}{ Association w/ SCl } \\
\cline { 3 - 4 } Compensation For & Cases & $2(1)$ & p Value \\
\hline Brain injury & 312 & 11.05 & 0.0009 \\
\hline Spine injury & 312 & 53.0 & $<0.0001$ \\
\hline Mental illness & & & $\mathrm{NS}$ \\
\hline
\end{tabular}

NS = not significant. 


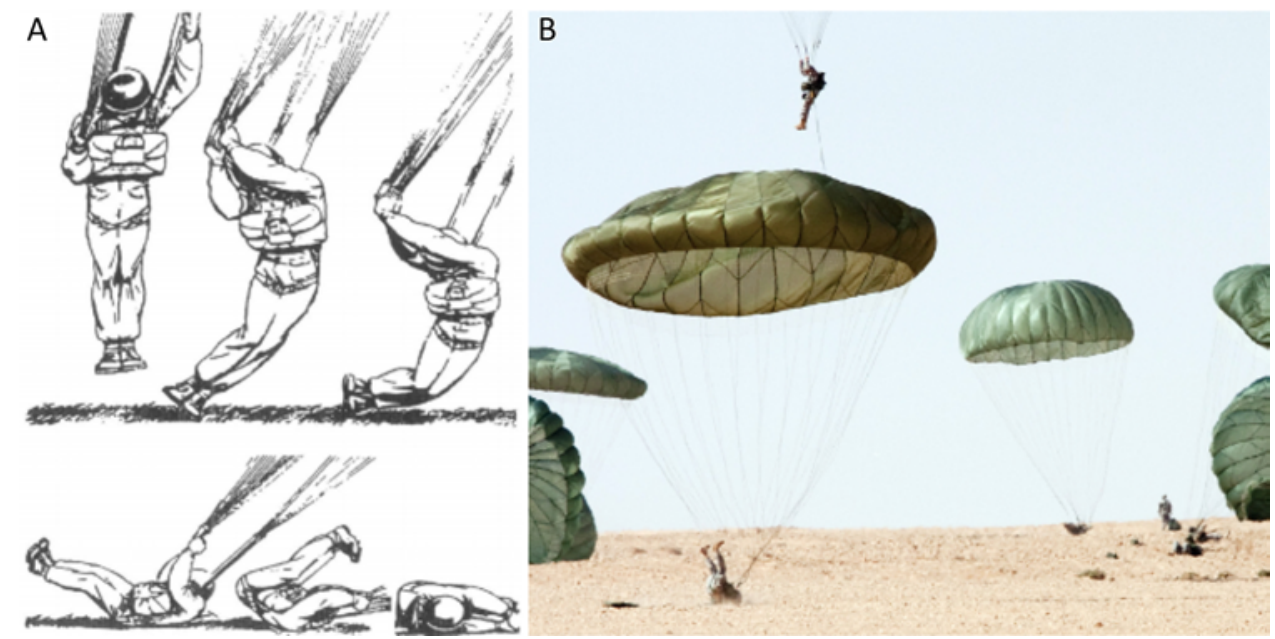

FIG. 4. A: Diagram for performing a "parachute landing fall," a maneuver that dissipates the energy of impact. Adapted from Bricknell MC, Craig SC. Occup Med (Lond). 1999;49(1):17-26. @The Author(s) 2020. Published by Oxford University Press on behalf of the Society of Occupational Medicine. All rights reserved. B: Parachute landing fall in US Army drop zone landing training. https://www.flickr.com/photos/soldiersmediacenter/4367407655; CC BY 2.0 license (https://creativecommons.org/ licenses/by/2.0/). Figure is available in color online only.

descents, type of dropping zones, and more..$^{12}$ Prior research has found that nighttime descents with equipment have the highest risk of injury. ${ }^{27}$ Nevertheless, these risks are inherent and necessary to military operations and cannot be fully eliminated. However, the continued high rate of SCI noted in our analysis indicates the need for more understanding of the mechanisms as well as the implications for prevention.

Military trauma has historically served as the foundation for civilian trauma progress and interventions. Poignant examples include the treatment of penetrating head injuries and shock, as well as the establishment of rapid evacuation to regional trauma centers. ${ }^{2}$ SCIs sustained in modern-day warfare are often more clinically complex than those sustained in civilian life, largely due to the unique mechanisms of injury, polytrauma, and lack of access to immediate surgical and medical management in combat zones. ${ }^{28-30}$ While traumatic SCI in the general military population is often due to explosion, gunshot wound, helicopter accident, or motor vehicle collision, in civilians it is typically due to motor vehicle accidents or falls. ${ }^{10,31}$ Despite the etiological differences, at least one study has proposed that war-related SCI may be comparable to severe civilian SCI with polytrauma. ${ }^{32}$ An additional study has noted that low lumbar burst fractures are the principal fracture type of the spinal column seen in combatants. ${ }^{33}$ Thus, there are clearly military-to-civilian and civilian-tomilitary lessons in SCI, and this is especially true about evacuation systems. Unlike with some injuries such as mild TBI, medevac of SCIs may have significant long-term consequences, at least for a subset of patients with SCI. This cross-fertilization, specifically related to evacuation, suggests that the low medevac rate seen in our study may be a key focus for intervention. The development of the medevac system with crews able to provide advanced cardiac life support (ACLS) in the civilian setting stemmed from a necessity in military operations medicine. ${ }^{34}$
However, rescue evacuation efforts are exceedingly challenging for the SF operations given their hallmark unconventional guerrilla warfare tactics in hostile, unprotected enemy territories. Future efforts should be directed at either enhancing prevention through the engineering of protective equipment or implementing protocols for suspected SCI in the field. Knowing that SCI in SF occurs primarily from airborne operations is critical new information with impact for determining the type of emergency equipment required for treatment in the field (including cervical collars, spinal boards, vials of intravenous corticosteroids, vasopressors, etc.) and enhancing spinal trauma training of healthcare professionals who function in SF combat units. This finding warrants further studies to investigate and classify which SCIs in the field require prompt evacuation and medical or surgical treatment versus those that permit continuation of the mission. Additionally, postdeployment monitoring of patients with SCI should be emphasized, as these patients often have concomitant injuries requiring long-term care that can impede their return to service. ${ }^{35}$

The fact that a striking majority $(87.1 \%)$ of SF members were wearing headgear at the time of injury is noteworthy, especially given the association between SCI and TBI as well as between SCI and VA disability claims for brain injury. One possible explanation is the lack of sophisticated helmet technology optimized for airborne operations. This is relevant because SCI in our study was reported to be more common in pre-9/11 SF soldiers than in post-9/11 soldiers, and helmets have advanced since then. The fact that only $36.6 \%$ were wearing any type of body armor in airborne operations may again reflect the time frame in which these pre-9/11 SF members were being injured and the lack of routine body armor use at the time. Prior to the 1980s, and notably during the Vietnam War, flak jackets served as body armor, designed for protection against shrapnel and grenades, with little ballistic protection (Fig. 


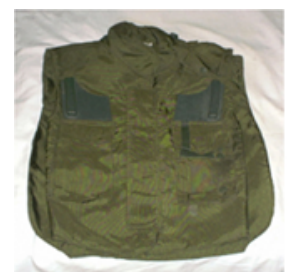

Flak Jacket

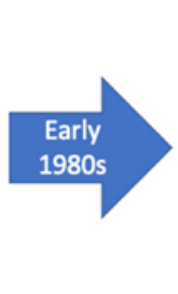$$
\text { Pe }
$$

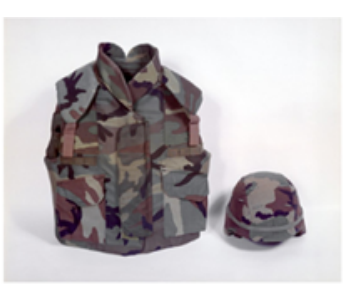

Personnel Armor System for Ground Troops

(PASGT)
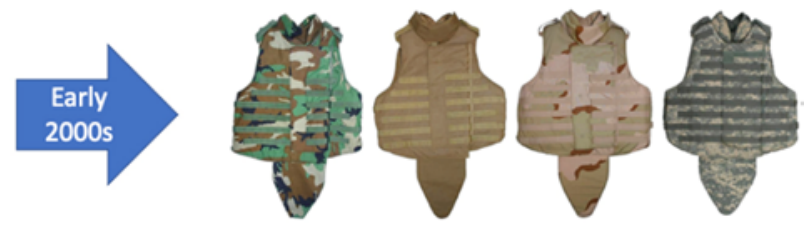

Interceptor Body Armor (IBA)

FIG. 5. Evolution of body armor. Left: Flak jacket. Source: https://en.wikipedia.org/wiki/File:Flakjacketparts.png; CC BY-SA 3.0 license (https://creativecommons.org/licenses/by-sa/3.0/). Center: Personnel Armor System for Ground Troops. Source: https:// commons.wikimedia.org/wiki/File:PASGT_vest_and_helmet,_1991.jpg; Work was produced by a US Army soldier or employee working as an employee of the US government. Public domain. Right: Interceptor Body Armor. Source: https://commons. wikimedia.org/wiki/File:Interceptor_Body_Armor_vests.png; CC BY-SA 3.0 unported license (https://creativecommons.org/ licenses/by-sa/3.0/deed.en). Figure is available in color online only.

5). From the 1980 s to the mid-2000s, the predominant body armor used was the Personnel Armor System for Ground Troops (PASGT), which offered ballistic protection using Kevlar. In the 2000s, the Interceptor Multi-Threat Body Armor System (IBA) replaced the PASGT for improved bullet and IED protection and has multiple enhanced iterations that are still used by US military personnel today. The increase in body armor use by post-9/11 SF is possibly contributing to their decreased, but still high, rate of SCI. In addition, airborne operations were more common overall in pre-9/11 warfare. The hallmark post-9/11 enemy tactic-detonating IEDs-has profoundly shifted the overall injury patterns sustained by US service members. ${ }^{28}$

The association of SCI with low sperm count, low testosterone, and erectile dysfunction is consistent with the literature on civilian SCI. Serious impairment in sexual and reproductive functions following SCI remains a paramount issue in the rehabilitation of these patients, regardless of whether they are military or civilian. ${ }^{36,37}$ Moreover, even though we found SCI to be significantly associated with having a diagnosed mental illness, it was not significantly associated with being compensated for such illnesses. Given the devastating nature of SCI, this lack of mental illness compensation for SF soldiers with SCI may be due to their "maxing out" of VA disability compensation. This hypothesis is corroborated by the significantly higher VA rating in SF soldiers sustaining SCI than in their non-SCI counterparts. The SF association of SCI with TBI may be linked to the high-impact landings of airborne operations or polytrauma associated with blast injuries, which is very similar to the link between SCI and TBI seen with vehicular accidents. ${ }^{6,38}$ This suggests that the model of blast injury may share many features with injuries sustained by hurtling unrestrained at high speeds as the etiology of injury.

This study design has several limitations, as in any survey. These limitations include the response rate, the potential for nonresponse bias, and the fact that SF members self-reported the clinical diagnosis. With respect to the low response rate, members of the US Army SF are often inaccessible given the nature of their operations and worldwide deployments. Reported SCI incidence may also be high, as SF soldiers may have incorrectly considered spine trauma, back injuries without SCI, or back pain as a diagnosis of
SCI. However, our research is the first investigation of $\mathrm{SCI}$ in the SF and therefore provides novel insight into the manifestation of this injury. The new knowledge obtained from this work should be of import to other branches of the Armed Forces for parachuting risks and may also inform civilian neurotrauma due to airborne accidents.

\section{Conclusions}

The study provides a special context and understanding of SCI in the US military, particularly in SF groups, given its unique etiologies, hallmark unconventional warfare tactics, and protective equipment. Body armor use has significantly increased in post-9/11 SF soldiers, yet there is seemingly still a need for better, optimized technologies for the prevention of SCI in the field.

\section{Acknowledgments}

We thank the staff at the US GBF (https://greenberetfoundation. org/) for their extensive assistance in participant recruitment and their guidance on devising survey questions related to military background and exposures. We also thank Colonel William J. Davis (ret), Lieutenant Colonel Dennis Downey (ret), and Sergeant First Class Mark Christianson (ret), of the US Army SF, for their invaluable counsel and knowledge related to global US military operations and associated injuries.

\section{References}

1. Grimm PD, Mauntel TC, Potter BK. Combat and noncombat musculoskeletal injuries in the US military. Sports Med Arthrosc Rev. 2019;27(3):84-91.

2. Fitzgerald GJ. Chemical warfare and medical response during World War I. Am J Public Health. 2008;98(4):611-625.

3. Atiyeh BS, Gunn SW, Hayek SN. Military and civilian burn injuries during armed conflicts. Ann Burns Fire Disasters. 2007;20(4):203-215.

4. Mccafferty RR, Neal CJ, Marshall SA, et al. Neurosurgery and medical management of severe head injury. Mil Med. 2018;183(suppl_2):67-72.

5. Ursano RJ, Kessler RC, Naifeh JA, et al. Frequency of improvised explosive devices and suicide attempts in the U.S. Army. Mil Med. 2017;182(3):e1697-e1703.

6. Schoenfeld AJ, Laughlin MD, McCriskin BJ, et al. Spinal injuries in United States military personnel deployed to Iraq and Afghanistan: an epidemiological investigation involving 
7877 combat casualties from 2005 to 2009. Spine (Phila Pa 1976). 2013;38(20):1770-1778.

7. Bernstock JD, Caples CM, Wagner SC, et al. Characteristics of combat-related spine injuries: a review of recent literature. Mil Med. 2015;180(5):503-512.

8. Abrams GM, Wakasa M. Chronic complications of spinal cord injury and disease. UpToDate. August 19, 2019. Accessed August 11, 2020. https://www.uptodate.com/contents/ chronic-complications-of-spinal-cord-injury-and-disease

9. Spotlight: Improving care for veterans with spinal cord injury and disorders. Health Services Research \& Development. Veterans Administration. April 2013. Accessed August 11, 2020. https://www.hsrd.research.va.gov/news/feature/sci.cfm

10. The US Green Beret Foundation. Accessed August 11, 2020. https://greenberetfoundation.org

11. Clancy T, Gresham J. Special Forces: A Guided Tour of U.S. Army Special Forces. Sidgwick \& Jackson; 2001.

12. Berwick D, Downey A, Cornett E, eds. A National Trauma Care System: Integrating Military and Civilian Trauma Systems to Achieve Zero Preventable Deaths After Injury. National Academies Press; 2016.

13. Rivera JC, Anderson ER, Jenne JW, Topp RF. Spine-related disability following combat injury. J Surg Orthop Adv. 2014; 23(3):136-139.

14. Furlan JC, Kurban D, Craven BC. Traumatic spinal cord injury in military personnel versus civilians: a propensity score-matched cohort study. J R Army Med Corps. Published online May 31, 2019. doi:10.1136/jramc-2019-001197

15. Furlan JC, Gulasingam S, Craven BC. Epidemiology of warrelated spinal cord injury among combatants: a systematic review. Global Spine J. 2019;9(5):545-558.

16. Chapter 1. Introduction. In: Airborne Operations Field Manual. No. 90-26. Headquarters, Department of the Army; 1990. https://usacac.army.mil/sites/default/files/misc/doctrine/ CDG/cdg_resources/manuals/fm/fm90_26.pdf

17. Kotwal RS, Meyer DE, O'Connor KC, et al. Army Ranger casualty, attrition, and surgery rates for airborne operations in Afghanistan and Iraq. Aviat Space Environ Med. 2004; 75(10):833-840.

18. Johnson ES, Gaydos SJ, Pavelites JJ, et al. U.S. Army parachute mishap fatalities: 2010-2015. Aerosp Med Hum Perform. 2019;90(7):637-642.

19. Bricknell MC, Craig SC. Military parachuting injuries: a literature review. Occup Med (Lond). 1999;49(1):17-26.

20. Steele JR, Mickle KJ, Whitting WJ. Preventing injuries associated with military static-line parachuting landings. In: Gefen A, Epstein Y, eds. The Mechanobiology and Mechanophysiology of Military-Related Injuries. Springer; 2016:50-55.

21. Knapik J, Steelman R. Risk factors for injuries during military static-line airborne operations: a systematic review and meta-analysis. J Athl Train. 2016;51(11):962-980.

22. Ball VL, Sutton JA, Hull A, Sinnott BA. Traumatic injury patterns associated with static line parachuting. Wilderness Environ Med. 2014;25(1):89-93.

23. Ciccone R, Richman RM. The mechanism of injury and the distribution of 3000 fractures and dislocations caused by parachute jumping. J Bone Joint Surg Am. 1948;30A(1):77-97.

24. Ivins BJ, Crowley JS, Johnson J, et al. Traumatic brain injury risk while parachuting: comparison of the personnel armor system for ground troops helmet and the advanced combat helmet. Mil Med. 2008;173(12):1168-1172.

25. Pirson J, Verbiest E. A study of some factors influencing military parachute landing injuries. Aviat Space Environ Med. 1985;56(6):564-567.

26. Lillywhite LP. Analysis of extrinsic factor associated with 379 injuries occurring during 34,236 military parachute descents. J R Army Med Corps. 1991;137(3):115-121.

27. Injury Prevention: Just the Facts. Parachuting Injuries. Army Public Health Center. Accessed August 11, 2020.
https://phc.amedd.army.mil/PHC\%20Resource\%20Library/ ParachutingInjuries_FS_12-006-1115.pdf

28. Schoenfeld AJ, Lehman RA Jr, Hsu JR. Evaluation and management of combat-related spinal injuries: a review based on recent experiences. Spine J. 2012;12(9):817-823.

29. Belmont PJ Jr, Goodman GP, Zacchilli M, et al. Incidence and epidemiology of combat injuries sustained during "the surge" portion of operation Iraqi Freedom by a U.S. Army brigade combat team. J Trauma. 2010;68(1):204-210.

30. Farr WD. The Death of the Golden Hour and the Return of the Future Guerrilla Hospital. Joint Special Operations University; 2017.

31. Furlan JC, Tator CH. Global epidemiology of traumatic spinal cord injury. In: Morganti-Kossman C, Raghupathi R, Maas A, eds. Traumatic Brain and Spinal Cord Injury: Challenges and Developments. 1st ed. Cambridge University Press; 2012:216-228.

32. Blair JA, Patzkowski JC, Schoenfeld AJ, et al. Are spine injuries sustained in battle truly different? Spine J. 2012;12(9):824-829.

33. Lehman RA Jr, Paik H, Eckel TT, et al. Low lumbar burst fractures: a unique fracture mechanism sustained in our current overseas conflicts. Spine J. 2012;12(9):784-790.

34. Kellerman A, Elster E, Rasmussen T. How the US military reinvented trauma care and what this means for US medicine. Health Affairs. July 3, 2018. Accessed August 11, 2020. https: //www.healthaffairs.org/do/10.1377/hblog20180628.431867/ full/

35. Furlan JC, Gulasingam S, Craven BC. The health economics of the spinal cord injury or disease among veterans of war: a systematic review. J Spinal Cord Med. 2017;40(6):649-664.

36. Bauman WA, La Fountaine MF, Spungen AM. Age-related prevalence of low testosterone in men with spinal cord injury. J Spinal Cord Med. 2014;37(1):32-39.

37. Patki P, Woodhouse J, Hamid R, et al. Effects of spinal cord injury on semen parameters. J Spinal Cord Med. 2008;31(1): 27-32.

38. Sommer JL, Witkiewicz PM. The therapeutic challenges of dual diagnosis: TBI/SCI. Brain Inj. 2004;18(12):1297-1308.

\section{Disclosures}

Dr. Benzil is a founding partner of Benzil Zusman, LLC (not related to the content of this study). Dr. Hadjipanayis is a medical advisor to NX Development Corp., is entitled to royalties from NX Development Corp., and is a consultant to Synaptive Medical (not related to the content of this study).

\section{Author Contributions}

Conception and design: Kessler, Bhammar. Acquisition of data: Bhammar. Analysis and interpretation of data: Kessler, Bhammar, Rasouli. Drafting the article: Kessler, Bhammar, Rasouli, Benzil. Critically revising the article: Kessler, Bhammar, Lakomkin, Shrivastava, Rasouli, Steinberger, Hadjipanayis, Benzil. Reviewed submitted version of manuscript: Kessler, Bhammar. Approved the final version of the manuscript on behalf of all authors: Kessler. Statistical analysis: Bhammar. Study supervision: Bederson, Hadjipanayis, Benzil.

\section{Supplemental Information}

\section{Previous Presentations}

Portions of this work were presented at the Annual Meeting of the AANS/CNS Section on Disorders of the Spine and Peripheral Nerves held in Las Vegas, NV, on March 5-7, 2020.

\section{Correspondence}

Remi A. Kessler: Icahn School of Medicine at Mount Sinai, New York, NY.remi.kessler@icahn.mssm.edu. 